\title{
Predicting the evolution of neck pain episodes in routine clinical practice
}

\author{
Francisco M. Kovacs ${ }^{1,2^{*}} \mathbb{D}^{\mathbb{D}}$, Jesús Seco-Calvo ${ }^{2,3,4}$, Borja M. Fernández-Félix ${ }^{2,5,6}$, Javier Zamora ${ }^{2,5,6,7}$, Ana Royuela ${ }^{2,5,8}$ and \\ Alfonso Muriel ${ }^{2,5,6}$
}

\begin{abstract}
Background: The objective of this study was to develop models for predicting the evolution of a neck pain (NP) episode.

Methods: Three thousand two hundred twenty-five acute and chronic patients seeking care for NP, were recruited consecutively in 47 health care centers. Data on 37 variables were gathered, including gender, age, employment status, duration of pain, intensity of NP and pain referred down to the arm (AP), disability, history of neck surgery, diagnostic procedures undertaken, imaging findings, clinical diagnosis, and treatments used. Three separate multivariable logistic regression models were developed for predicting a clinically relevant improvement in NP, AP and disability at 3 months.

Results: Three thousand one (93.5\%\%) patients attended follow-up. For all the models calibration was good. The area under the ROC curve was $\geq 0.717$ for pain and 0.664 for disability. Factors associated with a better prognosis were: a) For all the outcomes: pain being acute (vs. chronic) and having received neuro-reflexotherapy. b) For NP: nonspecific pain (vs. pain caused by disc herniation or spinal stenosis), no signs of disc degeneration on imaging, staying at work, and being female. c) For AP: nonspecific NP and no signs of disc degeneration on imaging. d) For disability: staying at work and no signs of facet joint degeneration on imaging.
\end{abstract}

Conclusions: A prospective registry can be used for developing valid predictive models to quantify the odds that a given patient with NP will experience a clinically relevant improvement.

\section{Background}

Neck pain (NP) is defined as pain in the neck with or without pain referred into one or both upper limbs ("arm pain" -AP-). Worldwide, the point prevalence of $\mathrm{NP}$ is $4.9 \%$ (95\% CI 4.6 to 5.3 ), and it is one of the top five chronic pain conditions in terms of prevalence and years lost to disability [1-3].

Most episodes of acute NP improve spontaneously, but more than $30 \%$ of patients show some persistent or recurrent symptoms 1 year later [3]. Early identification of patients at higher risk of pain becoming chronic, would help select those in whom more aggressive treatments are worth considering. Therefore, the development of prediction rules in this field has been

\footnotetext{
* Correspondence: fmkovacs@kovacs.org

${ }^{1}$ Unidad de la Espalda Kovacs, Hospital Universitario HLA-Moncloa. University Hospital, Avenida de Menéndez Pelayo, 67, 28009 Madrid, Spain

${ }^{2}$ Spanish Back Pain Research Network, Madrid, Spain

Full list of author information is available at the end of the article
}

recommended as a research priority [4]. Unfortunately, many of the existing prediction rules derive from studies with small samples, or from re-analyses of data gathered in experimental studies, which may produce results that differ from those in routine practice [5].

Data from registries implemented in routine practice could be useful to develop prediction rules factoring in each patient's personal and clinical characteristics, including treatments received. This would also empower patients for informed shared decision making [5].

Ideally, registries should include virtually all the patients, gather valid, reliable and clinically relevant data, and ensure that losses to follow-up are kept to a minimum. Concerns have been expressed with regard to the feasibility of these requirements in routine clinical practice [6].

Therefore, the objectives of this study were; a) to explore the feasibility of implementing a registry of patients treated for NP in routine practice, b) use it to 
develop predictive models in order to quantify the likelihood that a given patient experiences a clinically relevant improvement in NP, arm pain and disability, and c) to assess such predictive models.

\section{Methods Setting}

Forty-seven health care centers were selected by the Spanish Back Pain Research Network to be invited to participate in this study, based on their past involvement in research on neck and low back pain. The centers were located across 11 out of the 17 Administrative regions in the country (Andalucía, Aragón, Asturias, Baleares, Castilla-León, Cataluña, Extremadura, Galicia, Madrid, Murcia, Vascongadas). The population of these regions is $35,776,167$, approximately $77 \%$ of the total population of the country [7].

Fifteen centers belonged to the Spanish National Health Service (SNHS), 6 to not-for-profit institutions working for the SNHS, and 26 were private. They included 8 primary care centers, 18 physical therapy practices, and 21 specialty Services in rheumatology (5), rehabilitation (6), neuroreflexotherapy (4), and orthopedic surgery (6).

\section{Subjects}

The inclusion and exclusion criteria were as follows.

Inclusion criteria: a) Seeking care for NP in a participating unit, b) suffering from neck pain, with or without pain in the arm, unrelated to trauma or systemic disease, and c) proficiency in Spanish.

Pain unrelated to systemic disease was defined as pain unrelated to cancer or inflammatory disease (e.g., rheumatoid arthritis), in patients who did not present signs suggesting fibromyalgia (defined as diffuse pain with unexplained fatigue or sleep disturbances) or "red flags" for latent systemic diseases. "Red flags" were defined as "oncologic disease during the previous 5 years, constitutional symptoms -unexplained weight loss, fever, chills-, history of intravenous drug use, or immunocompromised host" [8-11]. Patients with "red flags" could be included in the study if the appropriate diagnostic test had ruled out the presence of systemic diseases.

Patients who were included were asked to sign an informed consent, authorizing the use of demographic and clinical data related to their care for the purpose of this study.

Exclusion criteria were: central nervous system disorders (treated or untreated), other causes of referred or radiated pain in the arm (e.g., peripheral nerve damage) and not having signed the informed consent.
In order to analyze the influence of up to 40 variables, the sample had to include at least 400 subjects who would not experience improvement [12]. Approximately $80-85 \%$ of patients with spinal pain, experience a clinically relevant improvement in pain, referred pain and disability, at 3 months, while losses to follow-up at that period range between 5 and 10\% [13-16]. Therefore, sample size was established at 2934 subjects. There were no concerns about the sample size being too large, due to the observational nature of the study.

\section{Procedure}

Since this study did not require any changes to standard clinical practice, according to the Spanish law it was not subject to approval by an Institutional Review Board. All procedures followed were in accordance with the ethical standards of the Helsinki Declaration of 1975, as revised in 1983.

As per standard practice in Spain, patients and clinicians received no compensation for participating in this study.

Patients were recruited consecutively at the participating centers. All patients seeking care for NP were screened for inclusion and exclusion criteria.

All patients complying with inclusion criteria were invited to participate, and all those who accepted to sign the informed consent were included. Recruiting clinicians explained to eligible patients the importance of answering fully and accurately a series of questionnaires assessing their clinical status, and complying with the follow-up visit for an assessment of their evolution.

Patients were assessed upon recruitment and at follow-up. The follow-up assessment was planned at 3 months because: a) this study sought to analyze the outcome of a single episode of neck pain rather than relapses, b) this timeframe implies that all patients who are symptomatic at follow-up, would be chronic [17]; c) existing studies conducted in the environment where this study took place, have shown that losses to follow-up remain minimal for periods of up to 3 months $[15,18,19]$, rise at 6 months [20-22], and become increasingly significant thereafter $[13,23]$.

Patients were asked to complete the self-administered questionnaires at both assessments. Questionnaires were completed in private, with no interference from health care personnel or any other actors. Data from the questionnaires were inserted into a database by a team of auxiliary personnel with no connection to the treating physician. In order to make clinical decisions, the treating clinicians had access to that information, but were not able to alter the data. Participating in this study did not imply any changes to patients' clinical management, and clinicians were instructed to manage their patients as usual. 


\section{Variables}

This registry used the same variables and measuring instruments as the only registry of neck and back pain patients available in Spain. The latter was originally developed for post-marketing surveillance of a minimally invasive technology ("neuro-reflexotherapy"), and has shown to be reliable and lead to low proportions of missing data and losses to follow-up [14, 16, 24].

The registry gathered data from patients and from clinicians. Data requested from patients at the first assessment, were: gender, age (date of birth), duration of the current pain episode (date of pain appearance), time elapsed since the first episode (years), and employment status (classified as working, on sick leave, receiving disability compensation, student, housewife, unemployed, retired, or other; at the analysis phase, these categories were collapsed into: "working", "receiving financial compensation for NP" -on sick leave or disabled for that reason-, or "non worker" -any other status-).

At both assessments, patients were asked to report pain and disability, which are considered two of the main outcome measures for patients with spinal pain [25]. To this end, they completed two separate $10-\mathrm{cm}$ visual analog scales for NP and AP (-VAS-, for which $0=$ no pain and $10=$ worst imaginable pain) [26], and a validated Spanish version of the Neck Disability Index (-NDI-, for which $0=$ no disability and $100=$ worst possible disability) [18].

Data requested from recruiting clinicians were: diagnostic procedures prescribed for the current episode (XRays, CT scan, MRI, EMG, other -blood analyses, scintigraphy, etc.-), patients' radiological findings on imaging procedures performed for the current or previous episodes, as reported by radiologists (disc degeneration, facet joint degeneration, scoliosis, difference in leg length, spondylolisis, spinal stenosis, annular tear, disc protrusion, disc herniation, other radiological findings, no findings), diagnosis (pain caused by disc herniation, spinal stenosis or "common non-specific NP"), and treatments undergone by the patient throughout the study (drugs -analgesics, NSAIDs, steroids, muscle relaxants, opioids, other drugs-, physiotherapy and rehabilitation -which were collapsed into a single category at the analysis phase, and were defined as any form of exercise, heat, cold, electrotherapy or hands-on techniques, such as massage or mobilization-, neuroreflexotherapy intervention -defined as the implantation of surgical material in specific areas of the skin, for up to 90 days- [27], surgery, other treatments -e.g., spinal injections-).

Pain caused by disc herniation or spinal stenosis, was diagnosed if radicular pain or neurologic signs existed, and were consistent with the location in which disc protrusion/herniation or spinal stenosis had been documented on MRI. Patients not fitting into these definitions, were classified as suffering from "common, non-specific NP".

\section{Analysis}

All the analyses were undertaken by a team of independent biostatisticians who had no contact or communication with the clinicians involved in this study.

For categorical variables, absolute and relative frequencies were calculated. When distribution was normal, values for continuous variables were described through their mean and standard deviation (SD). When their distribution departed from normality, median and percentiles 25 and 75 were used.

Reductions in VAS or NDI scores between the baseline and follow-up assessments, were considered to reflect improvement only if they were greater than the minimal clinically important change (MCIC). The MCIC for pain and disability has been established as 30\% of their baseline scores, with a minimum value of 1.5 for VAS and 7 NDI points for neck pain-related disability $[19,28]$. This implied that it was impossible for patients with baseline scores below these values, to show a clinically relevant improvement at follow-up.

For instance, it was impossible for a patient with a disability score smaller than the MCIC at baseline to experience improvement in disability, and including this patient's data into the model exploring factors associated with a clinically relevant improvement in disability could skew results. In the case of patients with baseline scores below the MCIC, lack of improvement could only be spotted if they experienced a worsening of pain or disability (i.e., an increase in the score at follow-up, as compared to baseline). Therefore, in the case of patients with a baseline score which was smaller than the MCIC for a given variable, only those who at discharge had shown to have experienced a worsening were included in the analyses.

Outcome measures were neck pain, arm pain and disability. In order to quantify the likelihood that a given patient would experience a clinically relevant improvement in these variables, three separate multivariable predictive logistic regression models were developed. Improvement in NP, AP or disability were the dependent variables, and the maximal models included: gender; age (in years); baseline intensity of NP (VAS points); baseline intensity of AP (VAS points); NPrelated disability at baseline (NDI percentage); duration of the current episode in days (number of days); duration of the current episode (classified as acute or chronic, with a cut-off limit at 90 days) [17]; time elapsed since the first episode (years), employment status ("working", which was the reference category, "non worker" or "receiving financial compensation for NP"); diagnostic tests undertaken at any moment during the study period (X-Rays, MRI, other); findings in imaging procedures undertaken during the study period or previous episodes (disc degeneration, facet joint degeneration, 
scoliosis, spondylolisis, spinal stenosis, disc protrusion, disc herniation, other findings, no findings); clinical diagnosis (pain caused by disc protrusion/hernia, pain caused by spinal stenosis, or non-specific, common neck pain); and treatments used during the study period (drugs -analgesics, NSAIDs, steroids, muscle relaxants, opioids, other-, physiotherapy, rehabilitation, neuroreflexotherapy, surgery).

The value $p>0.05$ was used to eliminate variables from the model, following a non-automatic backward strategy. Nomograms were developed to illustrate the results of the models [12].

The area under the ROC curve (AUC) was used to asess discrimination of the final models, and calibration was assessed using the Hosmer-Lemeshow test [12].

The selection of variables was validated by using bootstrapping: 100 bootstrap samples were drawn [29]. Sample size was estimated using the number of observations that contained no missing values $[29,30]$. The variables selected were displayed for each sample drawn, and the total number of times each variable was selected was counted [29].

Both the apparent performance of each bootstrap sample ("bootstrap performance") and the performance of the bootstrap model in the original sample ("test performance"), were determined. Overfitting was defined as the average difference between bootstrap performance and test performance [31].

The Stata/IC v15.1(StataCorp, 2017) was used for statistical analysis.

\section{Results}

All the 47 health care centers which were invited to participate in this study, accepted. All patients invited to participate in the study, agreed to sign the informed consent. All were included and none were excluded. Due to the multicenter design, when sample size was reached, 3225 patients had been included. The second assessment, which was planned 90 days after the first one, generally took place later (median $[\mathrm{p} 25 ; \mathrm{p} 75]=103$ [89;137] days), and 224 patients $(6.95 \%)$ were lost to follow up.

Among the 3001 patients who attended the follow-up, most were women $(74.2 \%)$, the median duration of their pain episode was 180 days, and their baseline median value for pain intensity was 6.6 VAS points for NP and 6.0 for AP, while their mean score for disability in the NDI was 37.2 (Table 1). The baseline characteristics of patients who were lost to follow up, were similar (data not shown).

At baseline, 2961 patients reported some degree of NP (i.e., VAS >0), 2188 reported some degree of AP, and 1500 reported some degree of disability (i.e., NDI $>0$ ). Data from 6 patients were excluded from the regression model on NP because their baseline scores were below the threshold required for any potential improvement to be "clinically relevant". For the same reason, data from 105 and 49 patients were excluded from the regression models on AP and disability, respectively. All the reasons leading to the exclusion of data from the regression models, are shown in Fig. 1.

Among the patients included in the corresponding models, $1716(72,3 \%)$ showed a clinically relevant improvement in NP at the 3 month assessment and the remaining 656 did not, while 507 patients $(51,6 \%)$ showed a clinically relevant improvement in disability and 476 did not (Table 2). Among the 1938 patients who reported pain referred down to the arm (AP) when entering the study, 1371(70.7\%) showed a clinically relevant improvement 3 months later, and 567 did not (Table 2).Conversely, AP appeared during the study period in 5 patients who had not reported it at baseline. Among these patients, median (p25;p75) VAS score for AP at the follow-up assessment was $3(2 ; 3)$.

The multivariable logistic regression model showed that the factors which, at baseline, predicted a clinically relevant improvement in NP 3 months later, were, from highest to lowest frequency in bootstrapping validation (Table 3a): being treated with neuro-reflexotherapy, pain being acute (vs. chronic), arm pain being less severe, working (vs. "receiving compensation assistance for NP" or "non-worker"), not showing signs of disc degeneration on imaging, suffering from "non-specific" pain (vs. pain caused by spinal stenosis or disc herniation/protrusion), being female, and suffering higher baseline intensity of neck pain. The assessment of the calibration of the model showed that the frequency of expected and observed probabilities of improvement were similar (Hosmer-Lemeshow test, $p=0.383$ ). Discrimination of the model was good, with an AUC of 0.718. Overfitting was 0.020.

Factors predicting a clinically relevant improvement in AP 3 months later, were: being treated with neuroreflexotherapy, arm pain being more severe, pain being acute (vs. chronic), not showing signs of disc degeneration on imaging, neck pain being less severe, and suffering from "non-specific" pain (vs. pain caused by spinal stenosis or disc herniation/protrusion) (Table 3b). The assessment of the calibration of the model showed that the frequency of expected and observed probabilities of improvement were similar (Hosmer-Lemeshow test, $p=$ 0.369). Discrimination of the model was good, with an AUC of 0.717. Overfitting was 0.030 .

Factors predicting a clinically relevant improvement in disability 3 months later, were: arm pain being less severe, being treated with neuro-reflexotherapy, working (vs. "receiving financial compensation for NP" or "non worker"), baseline disability being higher, not showing signs of facet joint degeneration on imaging, and pain 
Table 1 Characteristics of patients recruited, diagnostic tests and treatments used during the study

\begin{tabular}{|c|c|}
\hline Variables & $n=3001$ \\
\hline$\overline{\text { Gender (female) }^{\mathrm{a}}}$ & $2227(74.2)$ \\
\hline Age (years) ${ }^{b}$ & $50.3(16.0)$ \\
\hline \multicolumn{2}{|l|}{ Employment status $^{\mathrm{a}}$} \\
\hline Non worker & $1166(38.8)$ \\
\hline Active & $1453(48.4)$ \\
\hline Duration of the pain episode (days) ${ }^{c}$ & $180(90 ; 365)$ \\
\hline \multicolumn{2}{|c|}{ Duration of the pain episode categorized (days) ${ }^{a}$} \\
\hline Acute (<90 days) & $971(32.4)$ \\
\hline Chronic ( $\geq 90$ days) & $2030(67.6)$ \\
\hline \multicolumn{2}{|l|}{ Time elapsed since first episode ${ }^{a}$} \\
\hline$<1$ year & $648(21.6)$ \\
\hline $1-5$ years & $984(32.8)$ \\
\hline $5-10$ years & $677(22.6)$ \\
\hline$>10$ years & $572(19.1)$ \\
\hline Baseline intensity of neck pain (VAS) ${ }^{b}, d$ & $6.6(2.2)$ \\
\hline Baseline intensity of arm pain (VAS) ${ }^{b}$, e & $6.0(2.5)$ \\
\hline Baseline disability (NDI) ${ }^{b} f$ & $37.2(19.2)$ \\
\hline \multicolumn{2}{|l|}{ Diagnostic procedures during the episode ${ }^{a}$} \\
\hline X-Ray & $699(23.3)$ \\
\hline MRI & $602(20.1)$ \\
\hline $\mathrm{CT}$ scan & $40(1.3)$ \\
\hline EMG & $58(1.9)$ \\
\hline Other & $135(4.5)$ \\
\hline \multicolumn{2}{|l|}{ Imaging findings ${ }^{a}$} \\
\hline Disc degeneration & $1335(44.5)$ \\
\hline Facet joint degeneration & $230(7.7)$ \\
\hline Scoliosis & $135(4.5)$ \\
\hline Spinal stenosis & $63(2.1)$ \\
\hline Disc protrusion & $270(9.0)$ \\
\hline Disc herniation (extrusion) & $518(17.3)$ \\
\hline Other imaging findings & $388(12.9)$ \\
\hline No findings & $995(33.2)$ \\
\hline \multicolumn{2}{|l|}{ Clinical diagnosis } \\
\hline Spinal stenosis & $63(2.1)$ \\
\hline Disc herniation/protrusion & $665(22.2)$ \\
\hline Nonspecific syndrome & $2273(75.7)$ \\
\hline \multicolumn{2}{|l|}{ Treatments $^{a}$} \\
\hline Analgesics & $1959(65.3)$ \\
\hline NSAIDs & $1826(60.8)$ \\
\hline Steroids & $190(6.3)$ \\
\hline Muscle relaxants & $736(24.5)$ \\
\hline Opioids & $52(1.7)$ \\
\hline Other & $673(22.4)$ \\
\hline
\end{tabular}

Table 1 Characteristics of patients recruited, diagnostic tests and treatments used during the study (Continued)

\begin{tabular}{ll}
\hline Variables & $n=3001$ \\
\hline Non pharmacological treatments ${ }^{\mathrm{a}}$ & $175(5.8)$ \\
Physical therapy & $343(11.4)$ \\
Rehabilitation & $2580(86.0)$ \\
Neuro-reflexotherapy & $8(0.3)$ \\
$\quad$ Surgery & \\
Other treatments ${ }^{\mathrm{a}}$ & $3(0.1)$ \\
Rhizolysis & $13(0.4)$ \\
Epidural injections & $12(0.4)$ \\
Referral to pain unit & $31(1.0)$ \\
Other treatments &
\end{tabular}

a Frequency (\%) ${ }^{\mathrm{b}}$ Mean (sd) ${ }^{\mathrm{c}}$ Median (p25;p75) ${ }^{\mathrm{d}}$ :Patient with VAS for NP $>0$ $(n=2961)^{\mathrm{e}}$ :Patient with VAS for AP $>0(n=2188)^{\mathrm{f}}$ :Patient with NDI $>0(n=$ 1500) $)^{9}$ :Includes; ozone injections, spinal manipulation, acupuncture, and homeopathy,

being acute (vs. chronic) (Table 3c). The assessment of the calibration of the model showed that the frequency of expected and observed probabilities of improvement were similar (Hosmer-Lemeshow test, $p=0.480$ ). Discrimination of the model was poor, with an AUC of 0.664. Overfitting was 0.037 .

Figures 2, 3 and 4 show the nomograms corresponding to the models on improvement of NP, AP and disability.

\section{Discussion}

Results from this study show that it is feasible to implement a registry for NP patients treated in routine clinical practice. The registry included all patients seeking care for NP in the participating centers, where they were treated following standard practice in routine clinical practice. Clinically relevant data were gathered using previously validated methods $[14,16,18,24-26]$, and the proportion of losses to follow-up was below 7\%. Data from this registry make it possible to develop predictive models which are valid to determine the likelihood of improvement, factoring in patients' characteristics and clinical decisions, and nomograms to facilitate the use of these models in routine practice (Table 3, Figs. 2-4).

However, a registry analysis is an observational study, and "association" does not necessarily imply "causality". Therefore, results showing the association between a given variable and a better or worse prognosis should be interpreted cautiously, taking clinical plausibility into account. For instance, the association between staying at work and improvement in NP, which is consistent with results from previous studies on NP [32, 33], might be due to the fact that staying active improves the evolution of NP, and/or to the fact that subjects staying at work are those with a mental and personal attitude that are conducive to a better prognosis. 


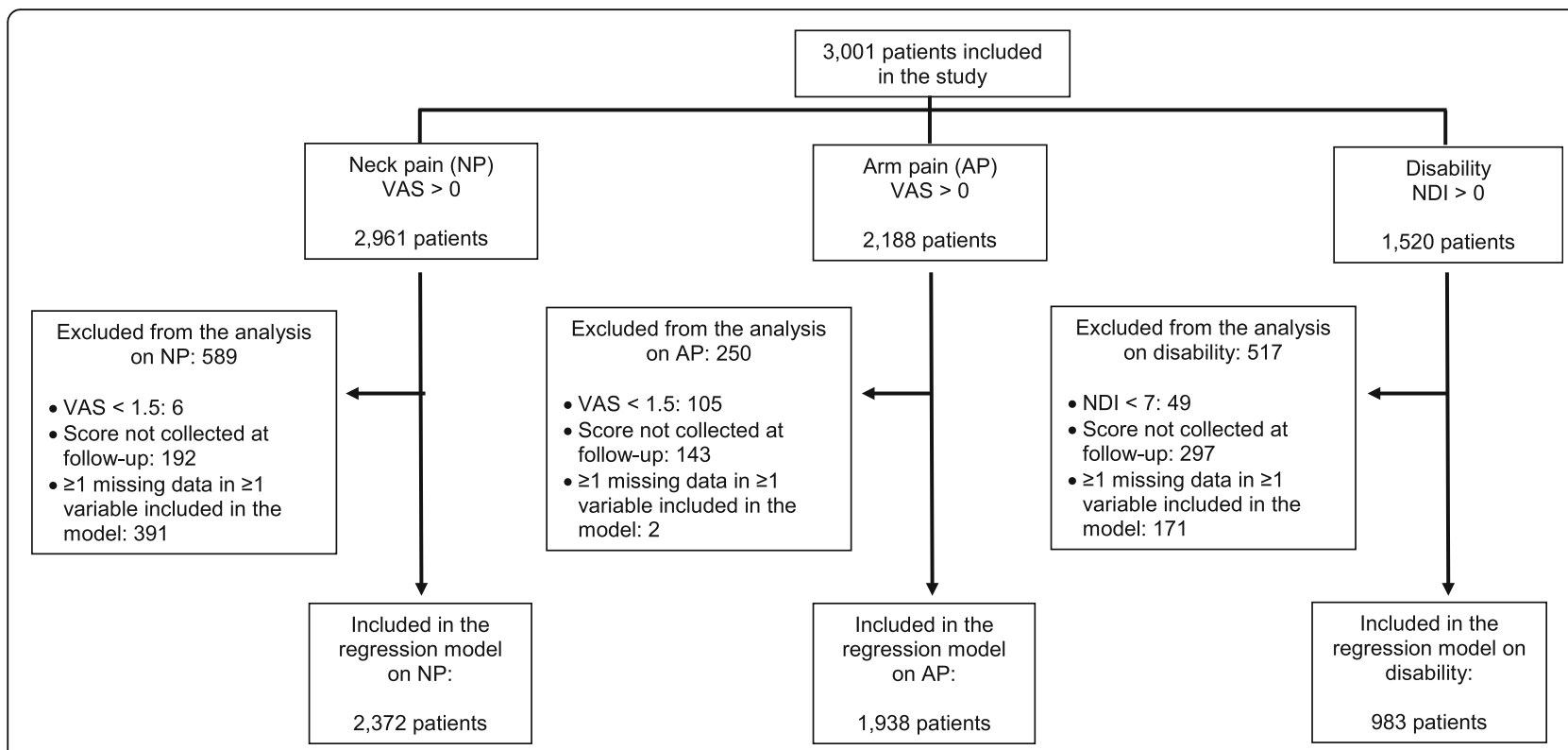

Fig. 1 Flow chart showing the number of patients whose data were included in the regression models

Nevertheless, results from this study are in line with those from previous studies and are clinically plausible; most imaging findings are unlikely to predict the clinical evolution of NP, AP or disability, unless there is a correlation between clinical and radiological findings [34]; radicular pain caused by symptomatic spinal stenosis or disc herniation is harder to treat than referred pain associated with common NP; irrespective of the treatments applied and other patient characteristics, chronic (vs. acute) pain is associated with a worse prognosis for pain and disability; neuro-reflexotherapy is associated with a significant improvement in pain and disability [16, 24, 27]; staying at work is associated with a better prognosis [32, 33]; and a higher baseline value for a given variable (NP, AP or disability) leaves more room for its improvement, whereas the prognosis is worse for patients who are more severely affected (in terms of the other variables).

It is likely that the evolution of disability is affected by additional variables which were not assessed in this registry. In fact, discrimination was good in the models on NP and AP, whereas it was poor in the model on disability. Additionally, baseline mean score for disability was mild, and in a significant number of patients it was below the value of the minimal clinically important change. As a result, the model on disability only included data from approximately $40 \%$ of the patients. Despite all of the above, for all models discrimination was $>0.663$ and calibration was acceptable, which suggests that nomograms may be applicable in clinical practice for early identification of patients who are at a higher risk of becoming chronic.
Many different treatment modalities are used for the treatment of NP, but very few are supported by solid evidence on efficacy or effectiveness deriving from high quality randomized controlled trials (RCTs) [3, 16, 35-49]. In fact, few RCTs on spinal pain have focused on NP [3], maybe because it is less prevalent than low back pain $[1,2]$. As a result, clinical practice in the NP field is largely driven by the results from RCTs on other pain conditions, mainly low back pain, and RCTs to assess the efficacy, effectiveness and cost-effectiveness of treatments for NP are suitable [3].

Registries cannot substitute RCTs, and are not valid for proving the efficacy or effectiveness of treatments. However, they can be useful to assess the prognostic value of procedures which have previously shown to be efficacious through appropriate randomized clinical trials, or are assumed to be effective based on the evidence on their effect in other types of spinal pain. None of the pharmacological groups which were analyzed in this study was associated with clinical improvement. This might be due to the fact that, for the treatment of patients with NP, drugs are essentially designed to offer symptomatic pain relief, while this study focused on the improvement of the pain episode at 3 months. For the same reason, the timeframe of this study may be inappropriate to capture the effect of treatments aiming to prevent relapse or requiring longer periods to have an effect, such as exercise or surgery.

Previous studies and systematic reviews on prognosis factors for neck pain vary substantially in design and 
Table 2 Characteristics of patients in whom neck pain, arm pain and disability improved and did not improve

\begin{tabular}{|c|c|c|c|c|c|c|}
\hline \multirow[t]{2}{*}{ Variables } & \multicolumn{2}{|c|}{ Improvement of neckpain } & \multicolumn{2}{|c|}{ Improvement of armpain } & \multicolumn{2}{|c|}{ Improvement of disability } \\
\hline & No $(n=656)$ & Yes $(n=1716)$ & No $(n=567)$ & Yes $(n=1371)$ & No $(n=476)$ & Yes $(n=507)$ \\
\hline$\overline{\left.\text { Gender }_{(f e m a l e}\right)^{\mathrm{a}}}$ & $505(77.0)$ & $1263(73.6)$ & $435(76.7)$ & $1053(76.8)$ & $345(72.5)$ & $360(71.0)$ \\
\hline Age $(\text { years })^{b}$ & $48.6(17.9)$ & $50.9(15.3)$ & $50.5(15.7)$ & $51.6(14.4)$ & $47.8(18.7)$ & $48.3(16.2)$ \\
\hline \multicolumn{7}{|l|}{ Employment status $^{\mathrm{a}}$} \\
\hline Not applicable & $374(57.0)$ & $695(40.5)$ & $267(47.1)$ & $457(33.3)$ & $314(66.0)$ & $269(53.1)$ \\
\hline Not working & $67(10.2)$ & $101(5.9)$ & $50(8.8)$ & $77(5.6)$ & $57(12.0)$ & $49(9.7)$ \\
\hline Working & $215(32.8)$ & $920(53.6)$ & $183(32.3)$ & $664(48.4)$ & $105(22.1)$ & $189(37.3)$ \\
\hline Duration of the pain episode (days) ${ }^{c}$ & $180(60 ; 365)$ & $180(90 ; 365)$ & $180(90 ; 365)$ & $240(90 ; 365)$ & $90(32.5 ; 195)$ & $120(60 ; 365)$ \\
\hline \multicolumn{7}{|c|}{ Duration of the pain episode categorized (days) ${ }^{a}$} \\
\hline Acute (<90 days) & $259(39.5)$ & $570(33.2)$ & $175(30.9)$ & $370(27.0)$ & $236(49.6)$ & $222(43.8)$ \\
\hline Chronic ( $\geq 90$ days) & $397(60.5)$ & $1146(66.8)$ & $392(69.1)$ & $1001(73.0)$ & $240(50.4)$ & $285(56.2)$ \\
\hline \multicolumn{7}{|l|}{ Time since first episode (years) ${ }^{a}$} \\
\hline$<1$ & $168(25.6)$ & 339 (19.8) & $110(19.4)$ & $245(17.9)$ & $146(30.7)$ & $144(28.4)$ \\
\hline $1-5$ & $242(36.9)$ & $571(33.3)$ & $209(36.9)$ & $470(34.3)$ & $179(37.6)$ & 169 (33.3) \\
\hline $5-10$ & $125(19.1)$ & 409 (23.8) & $125(22.1)$ & $336(24.5)$ & $80(16.8)$ & $90(17.8)$ \\
\hline$>10$ & $98(14.9)$ & $346(20.2)$ & $102(18.0)$ & $278(20.3)$ & $55(11.6)$ & $73(14.4)$ \\
\hline Baseline intensity of neck pain (VAS) ${ }^{b}$ & $6.0(2.4)$ & $6.7(2.2)$ & $6.6(2.1)$ & $7.1(1.9)$ & $5.6(2.3)$ & $6.1(2.3)$ \\
\hline Baseline intensity of arm pain (VAS) & $5.5(2.5)$ & $6.1(2.5)$ & $5.6(2.4)$ & $6.5(2.2)$ & $5.3(2.5)$ & $5.4(2.5)$ \\
\hline Baseline disability (NDI) ${ }^{b}$ & $34.1(20.5)$ & $37.0(18.6)$ & $39.5(20.0)$ & $41.8(16.5)$ & $32.8(19.0)$ & $38.4(18.4)$ \\
\hline \multicolumn{7}{|c|}{ Diagnostic procedures during the episode ${ }^{a}$} \\
\hline X-Ray & $122(18.6)$ & $457(26.6)$ & $118(20.8)$ & $348(25.4)$ & $80(16.8)$ & $101(19.9)$ \\
\hline MRI & $115(17.5)$ & $364(21.2)$ & $109(19.2)$ & $285(20.8)$ & $65(13.7)$ & $110(21.7)$ \\
\hline $\mathrm{CT}$ scan & $7(1.1)$ & $29(1.7)$ & $9(1.6)$ & $19(1.4)$ & $2(0.4)$ & $7(1.4)$ \\
\hline EMG & $15(2.3)$ & $27(1.6)$ & $17(3.0)$ & $27(2.0)$ & $14(2.9)$ & $9(1.8)$ \\
\hline Other & $36(5.5)$ & $71(4.1)$ & $39(6.9)$ & $60(4.4)$ & $29(6.1)$ & $19(3.8)$ \\
\hline \multicolumn{7}{|l|}{ Imaging findings $^{a}$} \\
\hline Disc degeneration & $303(46.2)$ & $659(38.4)$ & $312(55.0)$ & $602(43.9)$ & $266(55.9)$ & $294(58.0)$ \\
\hline Facet joint degeneration & $73(11.1)$ & $103(6.0)$ & $74(13.1)$ & $77(5.6)$ & $68(14.3)$ & $42(8.3)$ \\
\hline Scoliosis & $25(3.8)$ & $75(4.4)$ & $24(4.2)$ & $61(4.5)$ & $21(4.4)$ & $28(5.5)$ \\
\hline Spinal stenosis & $12(1.8)$ & $32(1.9)$ & $16(2.8)$ & $29(2.1)$ & $11(2.3)$ & $9(1.8)$ \\
\hline Disc protrusion & $75(11.4)$ & $95(5.5)$ & $76(13.4)$ & $115(8.4)$ & $52(10.9)$ & $40(7.9)$ \\
\hline Disc herniation (extrusion) & $112(17.1)$ & $234(13.6)$ & $123(21.7)$ & $245(17.9)$ & 79 (16.6) & $117(23.1)$ \\
\hline Other findings & $72(11.0)$ & $201(11.7)$ & 77 (13.6) & $168(12.3)$ & $58(12.2)$ & 99 (19.5) \\
\hline No findings & $131(20.0)$ & $756(44.1)$ & $116(20.5)$ & $587(42.8)$ & $14(2.9)$ & $29(5.7)$ \\
\hline \multicolumn{7}{|l|}{ Clinical diagnosis } \\
\hline Spinal stenosis & $12(1.8)$ & $32(1.9)$ & $16(2.8)$ & $29(2.1)$ & $11(2.3)$ & $9(1.8)$ \\
\hline Disc protrusión/Herniation & $164(25.0)$ & $285(16.6)$ & $173(30.5)$ & $302(22.0)$ & $117(24.6)$ & $143(28.2)$ \\
\hline Nonspecific syndrome & $480(73.2)$ & $1399(81.5)$ & $378(66.7)$ & $1040(75.9)$ & $348(73.1)$ & $355(70.0)$ \\
\hline \multicolumn{7}{|l|}{ Treatments } \\
\hline Analgesics & $419(63.9)$ & $1139(66.4)$ & $391(69.0)$ & $959(70.0)$ & $339(71.2)$ & $353(69.6)$ \\
\hline NSAIDs & $387(59.0)$ & $1062(61.9)$ & $352(62.1)$ & $888(64.8)$ & $310(65.1)$ & $347(68.4)$ \\
\hline Steroids & $60(9.2)$ & $98(5.7)$ & & & $53(11.1)$ & $42(8.3)$ \\
\hline Muscle relaxants & $170(25.9)$ & $438(25.5)$ & $147(25.9)$ & $347(25.3)$ & $142(29.8)$ & $170(33.5)$ \\
\hline Opioids & $11(1.7)$ & $22(1.3)$ & $10(1.8)$ & $24(1.8)$ & $14(2.9)$ & $15(3.0)$ \\
\hline
\end{tabular}


Table 2 Characteristics of patients in whom neck pain, arm pain and disability improved and did not improve (Continued)

\begin{tabular}{|c|c|c|c|c|c|c|}
\hline \multirow[t]{2}{*}{ Variables } & \multicolumn{2}{|c|}{ Improvement of neckpain } & \multicolumn{2}{|c|}{ Improvement of armpain } & \multicolumn{2}{|c|}{ Improvement of disability } \\
\hline & No $(n=656)$ & Yes $(n=1716)$ & No $(n=567)$ & Yes $(n=1371)$ & No $(n=476)$ & Yes $(n=507)$ \\
\hline Other & $145(22.1)$ & $362(21.1)$ & $143(25.2)$ & $290(21.2)$ & $148(31.1)$ & $182(35.9)$ \\
\hline \multicolumn{7}{|c|}{ Non pharmacological treatments } \\
\hline Physical therapy & $38(5.8)$ & $100(5.8)$ & $33(5.8)$ & $72(5.3)$ & $24(5.0)$ & $28(5.5)$ \\
\hline Rehabilitation & $84(12.8)$ & $172(10.0)$ & $76(13.4)$ & $164(12.0)$ & $74(15.6)$ & $64(12.6)$ \\
\hline Neuro-reflexotherapy & $428(65.2)$ & $1574(91.7)$ & $419(73.9)$ & $1332(97.2)$ & $252(52.9)$ & $379(74.8)$ \\
\hline Surgery & $3(0.5)$ & $3(0.2)$ & $2(0.4)$ & $3(0.2)$ & $1(0.2)$ & $0(0.0)$ \\
\hline \multicolumn{7}{|l|}{ Other treatments } \\
\hline Rhizolysis & $1(0.2)$ & $2(0.1)$ & $1(0.2)$ & $2(0.1)$ & $2(0.4)$ & $1(0.2)$ \\
\hline Epidural injections & $2(0.3)$ & $9(0.5)$ & $2(0.4)$ & $8(0.6)$ & $3(0.6)$ & $4(0.8)$ \\
\hline Referral to pain unit & $7(1.1)$ & $4(0.2)$ & $7(1.3)$ & $4(0.3)$ & $9(1.9)$ & $2(0.4)$ \\
\hline Othertreatments $^{d}$ & $3(0.5)$ & $17(1.0)$ & $5(0.9)$ & $11(0.8)$ & $4(0.8)$ & $7(1.4)$ \\
\hline
\end{tabular}

${ }^{a}$ Frequency (\%). ${ }^{b}$ Mean (sd). ${ }^{c}$ Median (p25;p75). ${ }^{d}$ Includes; injections of ozone, spinal manipulation, acupuncture, and homeopathy

setting, and methodological shortcomings have led to uncertainty about the reliability of the prognostic factors which have been suggested [4]. In fact, many original studies on prognostic factors are re-analyses of randomized controlled trials with relatively small samples, which aim to identify subsets of patients who respond better to some form of specific treatment [4]. This makes it inappropriate to compare their results with those from this study, in which a large population recruited in routine clinical practice and receiving a broad array of treatments, was analyzed.

The representativeness of the sample does not appear to be a major concern; recruiting centers were spread over 11 out of the 17 administrative regions existing in Spain, they included state-owned (i.e., "public") and private practices (both working for the Spanish National Health Service and for private institutions, both for profit and non for profit), and they included primary care, physical therapy and specialty centers. All patients seeking care in these practices were screened consecutively, all those who complied with inclusion criteria were included, none were excluded, losses to follow-up were below 7\%, and patients' characteristics are in line with the typical patient requesting care for neck pain (Table 1). However, since most spinal neck surgery in Spain is performed at Neurosurgery Departments, and none participated in this study, only 8 patients (0.3\%) underwent surgery, which makes this study unsuitable to assess the potential predictive value of spinal neck surgery on the evolution of a pain episode.

In fact, this study and the registry from which it derives, have a number of limitations. At the design phase of this study, it was decided that the sample should represent patients seeking health care for neck pain, reflecting prevalent (and not only incidental) cases. As a result, the sample included both patients with acute pain and those with (exacerbations of) chronic pain. The proportion of acute and chronic patients might have been different if the proportion of primary and specialty centers had been different.

Should the study have been conducted in a different setting, the proportion of patients receiving each form of treatment might also have been different. In fact, this study did not gather any data on the rationale for prescribing a specific treatment to a given patient. Therefore, such a rationale and how strictly the clinicians involved in this study followed indication criteria for each treatment, are unknown. However, this is usual in routine practice, and this study did not aim to assess the therapeutic effect of any treatments in experimental conditions, but their prognostic value in routine practice. Moreover, this study included a broad array of patients, recruited in both primary and specialty care centers, and the analysis made it possible to assess the association between each one of their characteristics and their prognosis for pain and disability. Future studies should explore the generalizability of these models to other cultural contexts.

In Spain, especially within the Government run health system (i.e., the National Health Service), patients are first seen by a primary care physician, who acts as a "gatekeeper", checks for the presence of "red flags" and refers patients with indication criteria for a specialized treatment to the appropriate specialist. Therefore, some treatments are almost exclusively applied in Services specialized in that given treatment (e.g., physical therapy, neuroreflexotherapy, rehabilitation or orthopedic surgery). This implies that, in this 
Table 3 Predictive models for improvement

\begin{tabular}{|c|c|c|c|}
\hline \multicolumn{4}{|c|}{ a. Predictive model for the improvement of neck pain $(n=2372)$, ${ }^{a}$} \\
\hline \multirow[t]{2}{*}{ Variables } & Odds ratio & \multirow[t]{2}{*}{ p } & \multirow[t]{2}{*}{ Frequency in bootstrapping validation ${ }^{c}(100)$} \\
\hline & (I.C. $95 \%)$ & & \\
\hline Being treated with neuro-reflexotherapy & $9.90(6.81 ; 14.38)$ & $<0.001$ & 100 \\
\hline Pain being chronic ( $\geq 90$ days) & $0.53(0.41 ; 0.70)$ & $<0.001$ & 98 \\
\hline Baseline intensity of arm pain (VAS) ${ }^{d}$ & $0.93(0.90 ; 0.97)$ & $<0.001$ & 95 \\
\hline \multicolumn{4}{|l|}{ Employment status (ref. working) } \\
\hline Non worker & $0.87(0.69 ; 1.10)$ & 0.259 & 94 \\
\hline Receiving financial compensation for neck pain & $0.48(0.33 ; 0.69)$ & $<0.001$ & 94 \\
\hline Signs of disc degeneration on imaging & $0.77(0.62 ; 0.95)$ & 0.017 & 68 \\
\hline \multicolumn{4}{|l|}{ Clinical diagnosis (ref. nonspecific pain) } \\
\hline Spinal stenosis & $0.78(0.39 ; 1.56)$ & 0.482 & 63 \\
\hline Disc herniation/protusion & $0.63(0.49 ; 0.81)$ & $<0.001$ & 63 \\
\hline Female & $0.77(0.61 ; 0.97)$ & 0.030 & 59 \\
\hline Baseline intensity of neck pain $(\mathrm{VAS})^{\mathrm{d}}$ & $1.06(1.00 ; 1.13)$ & 0.041 & 38 \\
\hline Constant & $0.84(0.60 ; 1.18)$ & 0.325 & - \\
\hline \multicolumn{4}{|c|}{ b. Predictive model for the improvement of pain referred down into the arm $(n=1938)$. ${ }^{e f}$} \\
\hline \multirow[t]{2}{*}{ Variables } & Odds ratio & \multirow[t]{2}{*}{ p } & \multirow[t]{2}{*}{ Frequency in bootstrapping validation ${ }^{9}(100$} \\
\hline & (I.C. 95\%) & & \\
\hline Being treated with neuro-reflexotherapy & $16.96(10.90 ; 26.37)$ & $<0.001$ & 100 \\
\hline Baseline intensity of arm pain (VAS) ${ }^{\mathrm{h}}$ & $1.17(1.10 ; 1.24)$ & $<0.001$ & 96 \\
\hline Pain being chronic ( $\geq 90$ days) & $0.57(0.43 ; 0.75)$ & $<0.001$ & 84 \\
\hline Signs of disc degeneration on imaging & $0.68(0.54 ; 0.85)$ & 0.001 & 83 \\
\hline Baseline intensity of neck pain $(\mathrm{VAS})^{d}$ & $0.91(0.85 ; 0.98)$ & 0.010 & 73 \\
\hline \multicolumn{4}{|l|}{ Clinical diagnosis (ref. nonspecific pain) } \\
\hline Spinal stenosis & $0.57(0.52 ; 0.86)$ & 0.088 & 56 \\
\hline Disc herniation/protrusion & $0.67(0.52 ; 0.86)$ & 0.002 & 56 \\
\hline Constant & $0.31(0.19 ; 1.24)$ & $<0.001$ & - \\
\hline \multicolumn{4}{|c|}{ c. Predictive model for the improvement for disability $(n=983)^{i . j}$} \\
\hline \multirow[t]{2}{*}{ Variables } & Odds ratio & \multirow[t]{2}{*}{$P$} & \multirow[t]{2}{*}{ Frequency in bootstrapping validation ${ }^{k}(100)$} \\
\hline & (I.C. 95\%) & & \\
\hline Baseline intensity of arm pain (VAS) $)^{\prime}$ & $0.89(0.85 ; 0.93)$ & $<0.001$ & 99 \\
\hline Being treated with neuro-reflexotherapy & $2.92(1.90 ; 4.49)$ & $<0.001$ & 97 \\
\hline \multicolumn{4}{|l|}{ Employment status (ref. working) } \\
\hline Non worker & $0.69(0.49 ; 0.97)$ & 0.031 & 90 \\
\hline Receiving financial compensation for neck pain & $0.45(0.28 ; 0.73)$ & 0.001 & 90 \\
\hline Baseline disability (NDI) ${ }^{\mathrm{m}}$ & $1.02(1.01 ; 1.02)$ & 0.002 & 84 \\
\hline Signs of facet joint degeneration on imaging & $0.60(0.39 ; 0.93)$ & 0.023 & 73 \\
\hline Pain being chronic ( $\geq 90$ days) & $0.65(0.46 ; 0.91)$ & 0.012 & 56 \\
\hline Constant & $0.89(0.59 ; 1.34)$ & 0.589 & - \\
\hline
\end{tabular}

${ }^{2}$ The number of patients who reported some degree of pain referred down to the arm (AP) at baseline (VAS $>0$ ), was 2961,6 had baseline scores below the cut-off for considering potential improvements as "clinically relevant", 583 had missing data at the baseline or the follow-up assessment, and 2372 were included in the model ${ }^{\mathrm{b}} \mathrm{AUC}=0.718(95 \% \mathrm{Cl} ; 0.694-0.742)$. Hosmer-Lemeshow: $\mathrm{chi}^{2}=0.383$

${ }^{c}$ Overfitting $=0.020$. Shrinkage factor $=0.906$

dVAS: Visual Analog Scale (range from better to worse; 0-10)

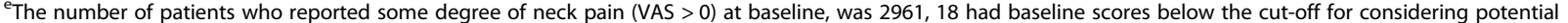
improvements as "clinically relevant", 238 had missing data at the baseline or the follow-up assessment, and 2372 were included in the model

${ }^{f} \mathrm{AUC}=0.717(95 \% \mathrm{Cl} ; 0.691-0.742)$. Hosmer-Lemeshow: $\mathrm{chi}^{2}=0.369$

${ }^{9}$ Overfitting $=0.030$. Shrinkage factor $=0.882$

hVAS: Visual Analog Scale (range from better to worse; 0-10)

iThe number of patients who reported some degree of disability at baseline (NDI >0), was 1500,49 had baseline scores below the cut-off for considering potential

improvements as "clinically relevant", 468 had missing data at the baseline or the follow-up assessment, and 983 were included in the model

${ }^{j} \mathrm{AUC}=0.677$ (95\%Cl; 0.644-0.711). Hosmer-Lemeshow: $\mathrm{chi}^{2}=0.128$

kOverfitting $=0.037$. Shrinkage factor $=0.787$

'VAS: Visual Analog Scale (range from better to worse; $0-10$ )

${ }^{\mathrm{m}} \mathrm{S}$ core on the Neck Disability Index (range from better to worse, $0-100$ ) 


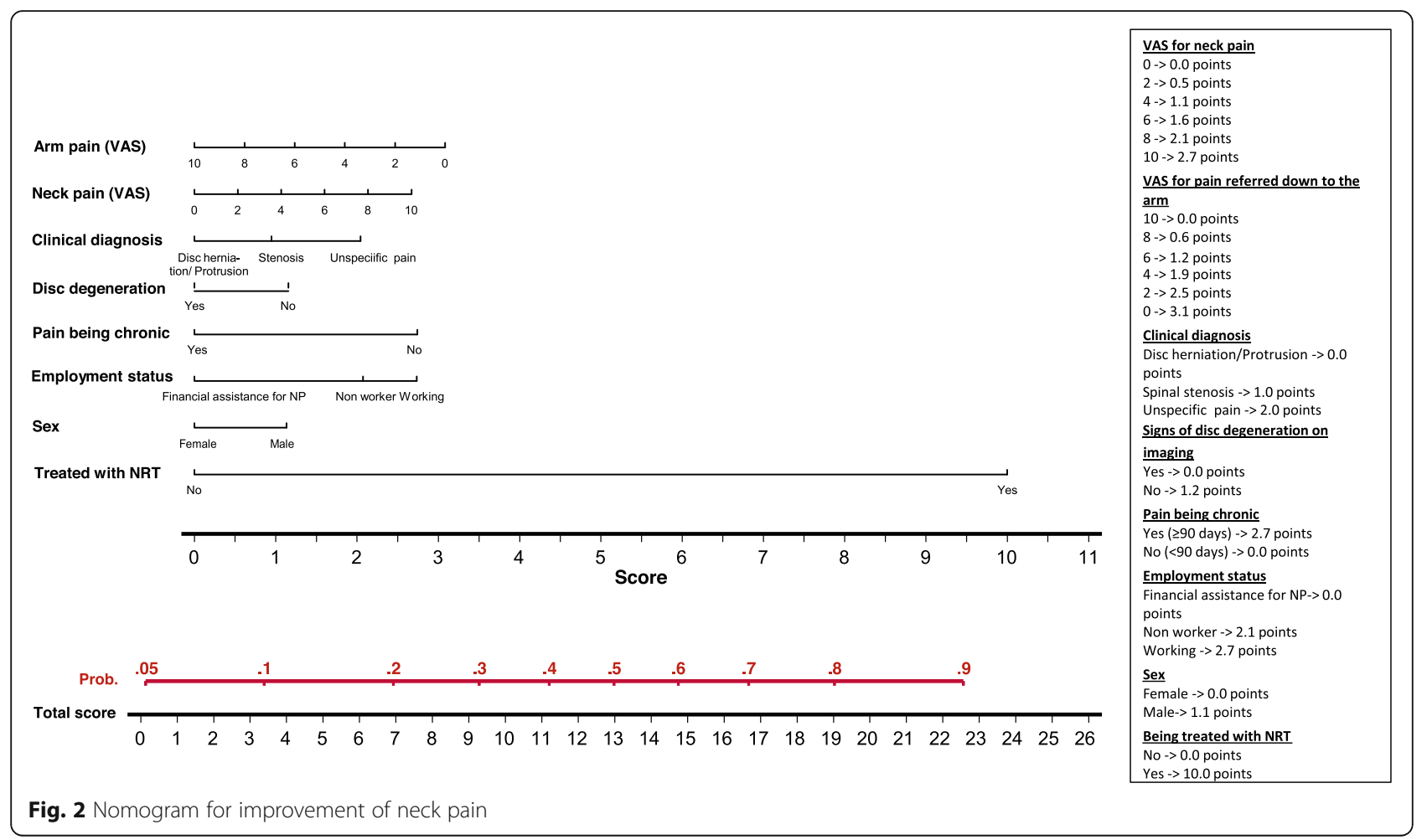

study, the prognostic value of being treated in one or other Service could not be explored because multicolinearity was detected between "treatment received" and "specialty". The prognostic value of the type of clinician who treats the patient should be explored in further studies, especially if conducted in settings where patients with neck pain are the main decision makers when deciding on the type of clinician they chose to seek care from.

Losses to follow up beyond 3 months in this register are unknown and should be assessed in further studies. This study focused on the clinical prognosis of a single NP episode, and analyzing factors associated with relapses was not within its scope and would require longer follow-up periods.

The health care centers invited to join this study were selected because of their previous involvement in research on spinal pain, and are not a random sample of health care centers. As a result, no neurosurgery practice was included in the sample, and participating clinicians may be more evidence-based in their practice than average, or more positively predisposed than average for implementing a registry on NP. Nevertheless, these centers represented a feasible and adequate platform to test run this registry in the context of routine practice, although It may be more difficult to implement registries in environments where the clinical community is less accustomed to e-health.
This registry did not include any psychological variables. This is due to the fact that, to date, the only psychological variables potentially influencing the prognosis of spinal pain which have been assessed in the Spanish cultural setting are fear avoidance beliefs and catastrophizing, and their influence has shown to be clinically irrelevant or null $[20,21,50]$. Nonetheless, pain is known to be a sensory and emotional experience which may be affected by psychological factors [51]. Therefore, psychological variables should be added to this registry as soon as future research identifies those with a prognostic value on neck pain in this setting.

\section{Conclusions}

Results from this study suggest that the probability that a patient with neck pain will experience improvements in neck pain, arm pain and disability within a 3 months period, can be quantified using the following data; baseline scores for neck pain, arm pain and disability, whether neck pain is acute or chronic, whether it is "nonspecific" (vs. caused by disc herniation or spinal stenosis), whether the patient is male or female, whether he/she is treated with neuro-reflexotherapy, whether he/ she stays at work (vs. does not work or receives financial compensation for neck pain), and whether he/she shows some specific images on MRI. 


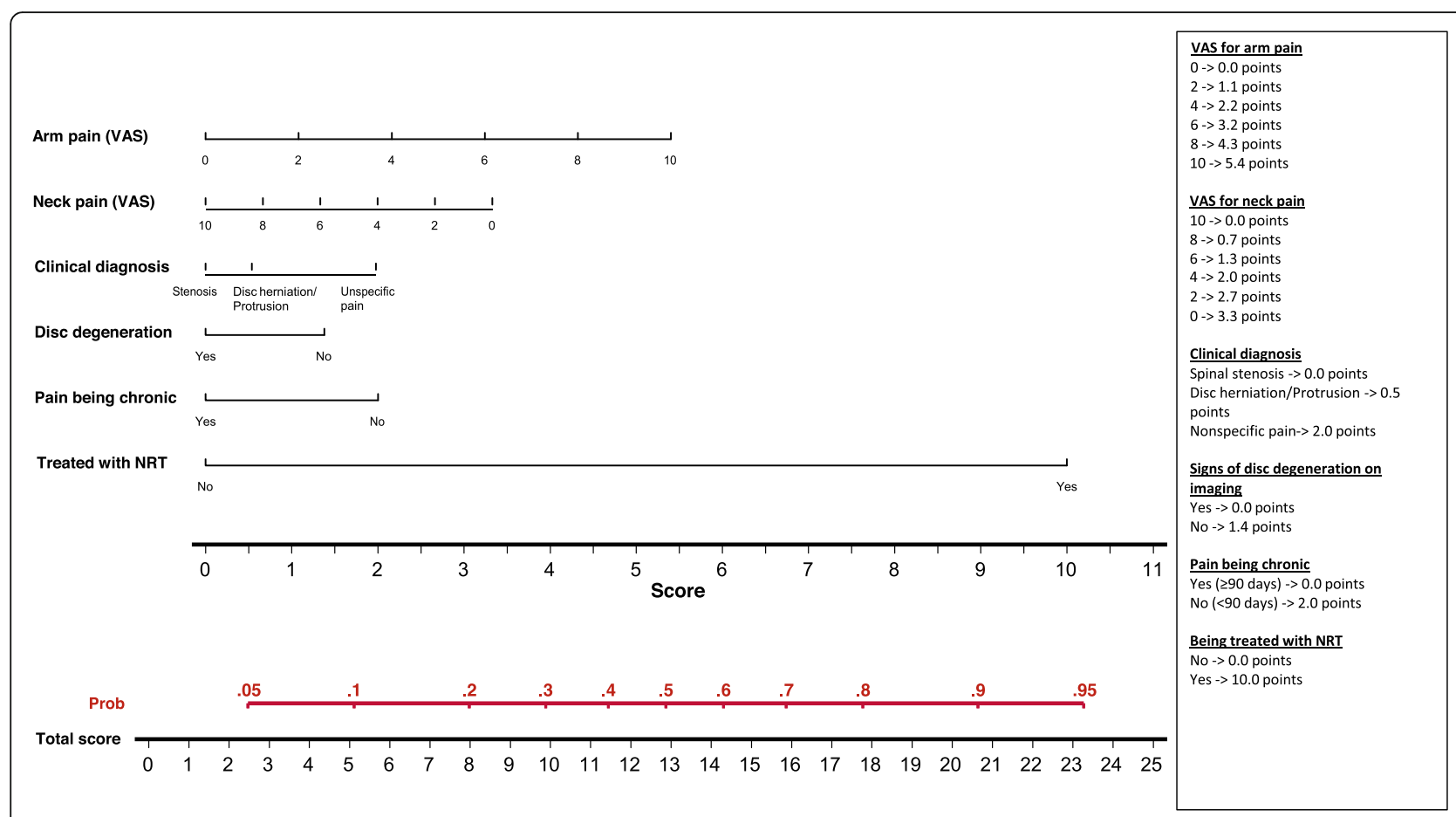

Fig. 3 Nomogram for improvement of arm pain

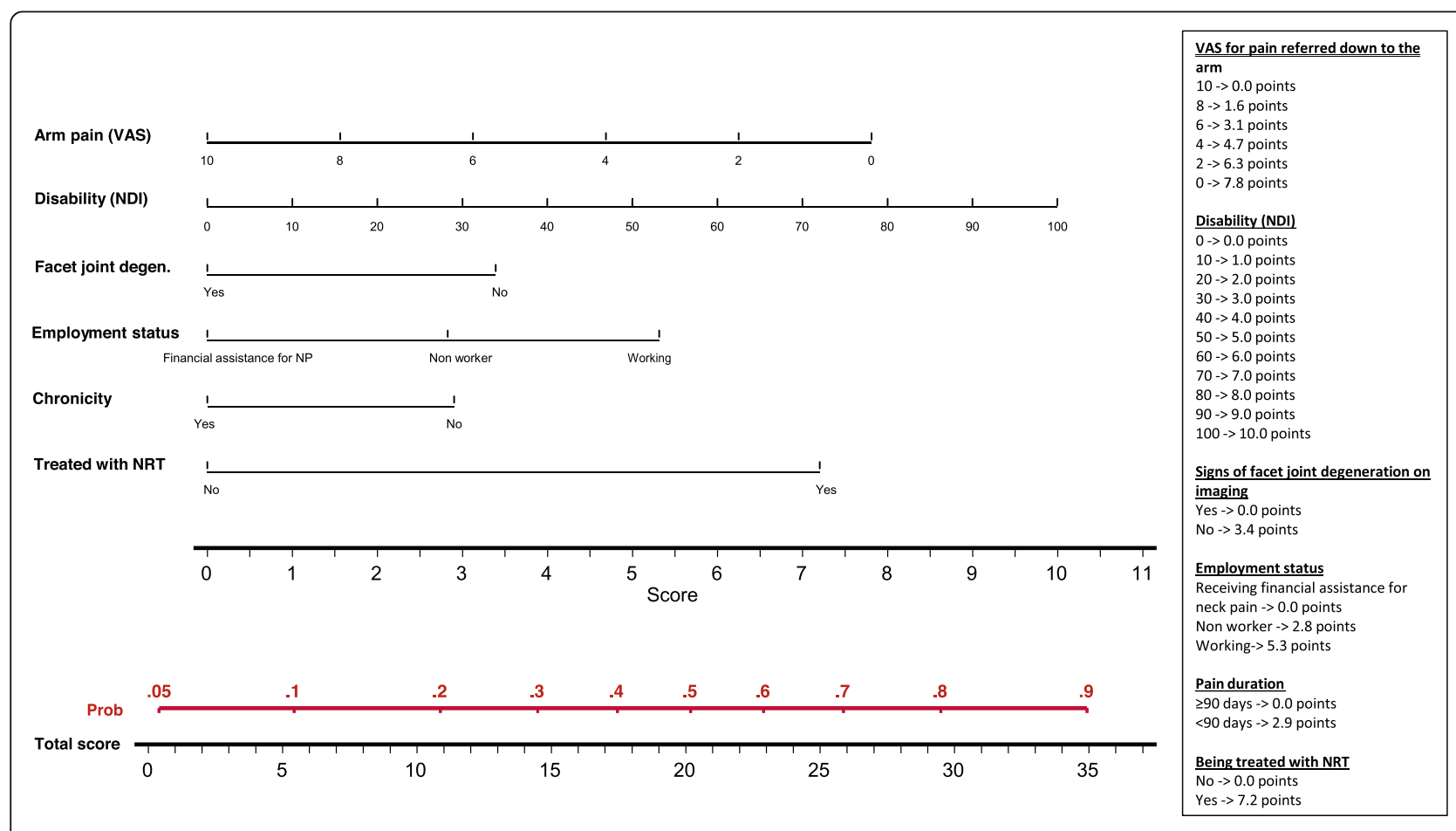

Fig. 4 Nomogram for improvement of disability 


\section{Abbreviations}

AP: Pain referred down to the arm; AUC: Area under the ROC curve; EMG: Electromyography; MCIC: Minimal clinically important change; MRI: Magnetic resonance imaging; NDI: Neck disability index; NP: Neck pain NSAIDs: Nonsteroidal anti-inflammatory drugs; RCT: Randomized controlled trial; ROC: Receiver operating characteristic; SD: Standard deviation; SNHS: Spanish National Health Service; VAS: Visual analog scale

\section{Acknowledgements}

Not applicable.

\section{Authors' contributions}

All the authors have contributed substantially to the conception and design of this study.JS and FMK have contributed to data gathering, and BMFF, AM, $A R$ and $J Z$, to data analysis and interpretation. FMK drafted the first version of this manuscript. All the authors have substantially revised it, and all of them have approved the submitted version. All authors accept public responsibility for this study and its conclusions, and each author has agreed both to be personally accountable for the author's own contributions and to ensure that questions related to the accuracy or integrity of any part of the work, even ones in which the author was not personally involved, are appropriately investigated, resolved, and the resolution documented in the literature.

\section{Funding}

This study was funded by the Spanish Back Pain Research Network (REIDE), a Spanish not-for-profit organization which specializes in neck and back pain research. REIDE is funded by: a) The Kovacs Back pain Unit in the Hospital Universitario HLA-Moncloa, a private organization specializing in neck and back pain, dedicated to medical research, health care and promotion of public health, with no links to the health industry b) Fundación ASISA, a Spanish non-profit institution linked to a health insurance company (ASISA) owned by a physician's cooperative.

The funding institutions had no role in the design and conduction of the study; data collection; management, analysis and interpretation of the data; preparation, review and approval of the manuscript; or the decision to submit the article for publication.

\section{Availability of data and materials}

The datasets analyzed during the current study are available from the corresponding author on reasonable request.

\section{Ethics approval and consent to participate}

According to the Spanish Law (Ley de Investigación Biomédica 14/2007 de 3 de julio, ORDEN SAS/3470/2009, de 16 de diciembre -BOE núm. 310, de 25 diciembre [RCL 2009, 2577]-), this study was not subject to approval by an Institutional Review Board because it was an observational study which did not require any changes to standard clinical practice, and data which were analyzed for the study did not contain any personal data which would allow the identity of patients to be revealed.

All procedures followed were in accordance with the ethical standards of the Helsinki Declaration of 1975, as revised in 1983.

Participants were asked for a written informed consent, which authorized the use of demographic and clinical data deriving from their care for the purpose of this study.

\section{Consent for publication}

Participants were asked for a written informed consent, which authorized the use of demographic and clinical data deriving from their care for the purpose of this study. Following standard practice in Spain, neither patients nor clinicians received any compensation for their participation in this study.

\section{Competing interests}

The authors declare that they have no competing interests.

\section{Author details}

${ }^{1}$ Unidad de la Espalda Kovacs, Hospital Universitario HLA-Moncloa. University Hospital, Avenida de Menéndez Pelayo, 67, 28009 Madrid, Spain. ${ }^{2}$ Spanish Back Pain Research Network, Madrid, Spain. Institute of Biomedicine (IBIOMED), University of León, Spain, León, Spain. ${ }^{4}$ University of the Basque Country, Spain.CampusUniversitario, 24071 León, Spain. ${ }^{5}$ CIBER Epidemiología y Salud Pública (CIBERESP), Madrid, Spain. ${ }^{6}$ Unidad de Bioestadística Clínica, Hospital Ramón y Cajal. IRICYS, Madrid, Spain. ${ }^{7}$ Barts and The London School of Medicine and Dentistry, Queen Mary University of London, London, UK. ${ }^{8}$ Clinical Biostatistics Unit, Puerta de Hierro University Hospital, Instituto de Investigación Puerta de Hierro (IDIPHISA), Madrid, Spain.

Received: 4 February 2019 Accepted: 21 November 2019

Published online: 26 December 2019

\section{References}

1. Hoy D, March L, Woolf A, Blyth F, Brooks P, Smith E, Vos T, Barendregt J, Blore J, Murray C, Burstein R, Buchbinder R. The global burden of neck pain: estimates from the global burden of disease 2010 study. Ann Rheum Dis. 2014;73(7):1309-15.

2. GBD 2015 Disease and Injury Incidence and Prevalence Collaborators. Global, regional, and national incidence, prevalence, and years lived with disability for 310 diseases and injuries, 1990-2015: a systematic analysis for the Global Burden of Disease Study 2015. Lancet. 2016;388(10053):1545-602

3. Cohen SP, Hooten WM. Advances in the diagnosis and management of neck pain. BMJ. 2017;358:j3221. https://doi.org/10.1136/bmj.j3221.

4. Kelly J, Ritchie C, Sterling M. Clinical prediction rules for prognosis and treatment prescription in neck pain: a systematic review. Musculoskelet Sci Pract. 2017;27:155-64.

5. Dreyer NA, Garner S. Registries for robust evidence. JAMA. 2009:302:790-1.

6. Schoene ML. Are patient registries ready for prime time? Back Letter. 2009; 11:121,126.

7. Instituto Nacional de Estadística (Spanish Statistics Office). Available at http://www.ine.es/dyngs/INEbase/listaoperaciones.htm. Accessed 23 June 2018

8. Deyo RA, Rainvile J, Kent DL. What can the history and physical examination tell us about low back pain? JAMA. 1992;268(6):760-5.

9. Slipman CW, Patel RK, Botwin K, Huston C, Zhang L, Lenrow D, Garvan C. Epidemiology of spine tumors presenting to musculoskeletal physiatrists. Arch Phys Med Rehabil. 2003;84(4):492-5.

10. van den Hoogen HMM, Koes BW, van EijkJThM BLM. On the accuracy of history, physical examination and erythrocyte sedimentation rate in diagnosing low back pain in general practice. A criteria-based review of the literature. Spine. 1995;20:318-27.

11. Downie A, Williams CM, Henschke N, Hancock MJ, Ostelo RW, de Vet HC, et al. Red flags to screen for malignancy and fracture in patients with low back pain: systematic review. BMJ. 2013;347:f7095. https://doi.org/10.1136/ bmj.f7095.

12. Harrell FE. Regression modeling strategies with applications to linear models, logistics regression, and survival analysis. New-York: Springer; 2001.

13. Kovacs FM, Fernández C, Cordero A, Muriel A, González-Luján L, Gil del Real MT. Non-specific low back pain in primary care in the Spanish National Health Service: a prospective study on clinical outcomes and determinants of management. BMC Health Serv Res. 2006;6:57.

14. Kovacs FM, Seco J, Royuela A, Corcoll J, Abraira V, and the Spanish Back Pain Research Network. Predicting the evolution of low back pain patients in routine clinical practice. Results from a registry within the Spanish National Health Service. Spine J. 2012;12:1008-20.

15. Kovacs FM, Seco J, Royuela A, Melis S, Sánchez C, Díaz-Arribas MJ, Meli M, Núnez M, Martínez-Rodríguez ME, Fernández C, Gestoso M, Mufraggi N, Moyá J, Rodríguez-Pérez V, Torres-Unda J, Burgos-Alonso N, GagoFernández I, Abraira V. Patients with neck pain are less likely to improve if they suffer from poor sleep quality. A prospective study in routine practice. Clin J Pain. 2015;31(8):713-21.

16. Royuela A, Kovacs FM, Campillo C, Casamitjana M, Muriel A, Abraira V. Predicting outcomes of neuroreflexotherapy in patients with subacute or chronic neck or low back pain. Spine J. 2014;14:1588-600.

17. Merskey H, Bogduk N. Description of chronic pain syndromes and definitions of pain terms. In: Classification of Chronic Pain. 2nd ed. Seattle: IASP Press; 1994

18. Kovacs FM, Bagó J, Royuela A, Seco J, Giménez S, Spanish Back pain research network. Psychometric characteristics of the Spanish version of instruments to measure neck pain disability. BMC Musculoskelet Disord. 2008;9:42. https://doi.org/10.1186/1471-2474-9-42.

19. Kovacs FM, Abraira V, Royuela A, Corcoll J, Alegre L, Tomás M, et al. Minimum detectable and minimal clinically important changes for pain in 
patients with nonspecific neck pain. BMC Musculoskelet Disord. 2008;9:43. https://doi.org/10.1186/1471-2474-9-43.

20. Kovacs FM, Muriel A, Abraira $V$, et al. The influence of fear avoidance beliefs on disability and quality of life is sparse in Spanish low back pain patients. Spine. 2005;30:E676-82.

21. Kovacs $F$, Abraira $V$, Santos $S$, et al. A comparison of two short education programs for improving low back pain-related disability in the elderly. A Cluster Randomized Controlled Trial. Spine. 2007;32:1053-9.

22. Albadalejo C, Kovacs FM, Royuela A, del Pino R, Zamora J, et al. The efficacy of a short education program and a short physiotherapy program for treating low back pain in primary care. A cluster randomized trial. Spine. 2010;35:483-96.

23. Kovacs FM, Llobera J, Abraira V, Lázaro P, Pozo F, Kleinbaum D, and the KAP Group. Effectiveness and cost effectiveness analysis of neuroreflexotherapy for subacute and chronic low back pain in routine general practice. A cluster randomized, controlled trial. Spine. 2002;27:1149-59.

24. Campillo C, Kovacs F. The use of risk sharing tools for post adoption surveillance of a non pharmacological technology in routine practice: results after one year. BMC Health Serv Res. 2013;13:181. https://doi.org/10. 1186/1472-6963-13-181.

25. Chiarotto A, Deyo RA, Terwee CB, Boers M, Buchbinder R, Corbin TP, et al. Core outcome domains for clinical trials in non-specific low back pain. Eur Spine J. 2015;24(6):1127-42.

26. Huskinson EC. Measurement of pain. Lancet. 1974;2:1127-31.

27. Urrutia G, Burton A, Morral A, Bonfill X, Zanoli G. Neuroreflexotherapy for nonspecific low back pain. Cochrane Database Syst Rev. 2004; (Issue 2): CD003009. https://doi.org/10.1002/14651858.CD003009.pub2.

28. Pool JJ, Ostelo RW, Hoving JL, Bouter LM, de Vet HC. Minimal clinically important change of the neck disability index and the numerical rating scale for patients with neck pain. Spine (Phila Pa 1976). 2007;32:3047-51.

29. Beyene J, Atenafu E, Hamid J, To T, Sung L. Determining relative importance of variables in developing and validating predictive models. BMC Med Res Methodol. 2009:9:64.

30. Garrett JM. SWBOOT: Stata module to bootstrap stepwise linear or logistic regression models. Available at http://ideas.repec.org/c/boc/bocode/s4156 01.html\#refs. Accessed 23 Feb 2012

31. Moons KG, Altman DG, Reitsma JB, loannidis JP, Macaskill P, Steyerberg EW, Vickers AJ, Ransohoff DF, Collins GS. Transparent reporting of a multivariable prediction model for individual prognosis or diagnosis (TRIPOD): explanation and elaboration. Ann Intern Med. 2015;162(1):W1-73.

32. Scuderi GJ, Sherman AL, Brusovanik GV, Pahl MA, Vaccaro AR. Symptomatic cervical disc herniation following a motor vehicle collision: return to work comparative study of workers' compensation versus personal injury insurance status. Spine J. 2005;5(6):639-44.

33. Rasmussen C, Leboeuf-Yde C, Hestbaek L, Manniche C. Poor outcome in patients with spine-related leg or arm pain who are involved in compensation claims: a prospective study of patients in the secondary care sector. Scand J Rheumatol. 2008;37(6):462-8.

34. Nakashima H, Yukawa Y, Suda K, Yamagata M, Ueta T, Kato F. Abnormal findings on magnetic resonance images of the cervical spines in 1211 asymptomatic subjects. Spine (Phila Pa 1976). 2015;40(6):392-8.

35. Chou R, Deyo R, Friedly J, Skelly A, Hashimoto R, Weimer M, Fu R, Dana T, Kraegel P, Griffin J, Grusing S, Brodt E. Noninvasive treatments for low back pain. Rockville: Agency for Healthcare Research and Quality (US); 2016. Report No:: 16-EHC004-EF. AHRQ Comparative Effectiveness Reviews

36. Cui X, Trinh K, Wang YJ. Chinese herbal medicine for chronic neck pain due to cervical degenerative disc disease. Cochrane Database Syst Rev. 2010;1: CD006556. https://doi.org/10.1002/14651858.CD006556.pub2.

37. Graham N, Gross A, Goldsmith CH, Klaber Moffett J, Haines T, Burnie SJ, Peloso PM. Mechanical traction for neck pain with or without radiculopathy. Cochrane Database Syst Rev. 2008;3:CD006408. https://doi.org/10.1002/ 14651858.CD006408.pub2.

38. Gross A, Forget M, St George K, Fraser MM, Graham N, Perry L, et al. Patient education for neck pain. Cochrane Database Syst Rev. 2012;3:CD005106. https://doi.org/10.1002/14651858.CD005106.pub4.

39. Gross A, Langevin P, Burnie SJ, Bédard-Brochu MS, Empey B, Dugas E, et al. Manipulation and mobilisation for neck pain contrasted against an inactive control or another active treatment. Cochrane Database Syst Rev. 2015;9: CD004249. https://doi.org/10.1002/14651858.CD004249.pub4.

40. Gross A, Kay TM, Paquin JP, Blanchette S, Lalonde P, Christie T, et al. Exercises for mechanical neck disorders. Cochrane Database Syst Rev. 2015; 1:CD004250. https://doi.org/10.1002/14651858.CD004250.pub5.
41. Hurwitz EL, Carragee EJ, van der Velde G, Carroll LJ, Nordin M, Guzman J, Peloso PM, Holm LW, Côté P, Hogg-Johnson S, Cassidy JD, Haldeman S, Bone and JointDecade 2000-2010 Task Forceon Neck Pain and Its Associated Disorders. Treatment of neck pain: noninvasive interventions: results of the bone and joint decade 2000-2010 task force on neck pain and its associated disorders. Spine (Phila Pa 1976). 2008;33(4 Suppl):S123-52.

42. Kroeling P, Gross A, Graham N, Burnie SJ, Szeto G, Goldsmith CH, et al. Electrotherapy for neck pain. Cochrane Database Syst Rev. 2013;8:CD004251. https://doi.org/10.1002/14651858.CD004251.pub5.

43. Langevin P, Peloso PM, Lowcock J, Nolan M, Weber J, Gross A. Botulinum toxin for subacute/chronic neck pain. Cochrane Database Syst Rev. 2011;(7): CD008626. https://doi.org/10.1002/14651858.CD008626.pub2

44. Monticone M, Cedraschi C, Ambrosini E, Rocca B, Fiorentini R, Restelli M, et al. Cognitive-behavioural treatment for subacute and chronic neck pain. Cochrane Database Syst Rev. 2015;(5):CD010664. https://doi.org/10.1002/ 14651858.CD010664.pub2.

45. Patel KC, Gross A, Graham N, Goldsmith CH, Ezzo J, Morien A, Peloso PM. Massage for mechanical neck disorders. Cochrane Database Syst Rev. 2012; (9):CD004871. https://doi.org/10.1002/14651858.CD004871.pub4.

46. Peloso P, Gross A, Haines T, Trinh K, Goldsmith C, Burnie S, Cervical Overview Group. Medicinal and injection therapies for mechanical neck disorders. Cochrane Database Syst Rev. 2007;(3):CD000319. Review. Update in: Cochrane Database Syst Rev. 2015;5:CD000319.

47. Shearer HM, Carroll LJ, Wong JJ, Côté P, Varatharajan S, Southerst D, et al. Are psychological interventions effective for the management of neck pain and whiplash-associated disorders? A systematic review by the Ontario protocol for traffic injury management (OPTIMa) collaboration. Spine J. 2016; 16(12):1566-81.

48. Sutton DA, Côté P, Wong JJ, Varatharajan S, Randhawa KA, Yu H, et al. Is multimodal care effective for the management of patients with whiplashassociateddisorders or neck pain and associated disorders? A systematic review by the Ontario protocol for traffic injury management (OPTIMa) collaboration. Spine J. 2016:16(12):1541-65.

49. Wong JJ, Shearer HM, Mior S, Jacobs C, Côté P, Randhawa K, et al. Are manual therapies, passive physical modalities, or acupuncture effective for the management of patients with whiplash-associated disorders or neck pain and associated disorders? An update of the bone and joint decade task force on neck pain and its associated disorders by the OPTIMa collaboration. Spine J. 2016;16(12):1598-630.

50. Kovacs FM, Seco J, Royuela A, Corcoll J, Peña A, and the Spanish Back Pain Research Network. The prognostic value of catastrophizing for predicting the clinical evolution of low back pain patients. A study in routine clinical practice within the Spanish National Health Service [NCT00502333]. Spine J. 2012:12:545-55.

51. Pincus T, Burton AK, Vogel S, Field AP. A systematic review of psychological factors as predictors of chronicity/disability in prospective cohorts of low back pain. Spine. 2002;27:E109-20.

\section{Publisher's Note}

Springer Nature remains neutral with regard to jurisdictional claims in published maps and institutional affiliations.

Ready to submit your research? Choose BMC and benefit from:

- fast, convenient online submission

- thorough peer review by experienced researchers in your field

- rapid publication on acceptance

- support for research data, including large and complex data types

- gold Open Access which fosters wider collaboration and increased citations

- maximum visibility for your research: over $100 \mathrm{M}$ website views per year

At BMC, research is always in progress.

Learn more biomedcentral.com/submission 